Waste and Resource Management Volume 167 Issue WR4

Business-to-business end-of-life IT industrial networks

Peagram, Williams, Curran et al.
Proceedings of the Institution of Civil Engineers

Waste and Resource Management 167 November 2014 Issue WR4

Pages 178-192 http://dx.doi.org/10.1680/warm.13.00023

Paper 1300023

Received 17/07/2013_Accepted 13/05/2014

Keywords: information technology/recycling \& reuse of materials/

waste management \& disposal

\title{
Business-to-business end-of-life IT industrial networks
}

\author{
Richard Peagram \\ Centre for Environmental Strategy (D3), University of Surrey, Guildford, \\ Surrey, UK \\ Ian D. Williams \\ Professor of Applied Environmental Science, Centre for Environmental \\ Sciences, Faculty of Engineering and the Environment, University of \\ Southampton, Southampton, UK \\ Tony Curran \\ Research Fellow, Centre for Environmental Sciences, Faculty of Engineering \\ and the Environment, University of Southampton, Southampton, UK \\ Sandra R. Mueller \\ Researcher, Centre for Environmental Sciences, Faculty of Engineering and \\ the Environment, University of Southampton, Southampton, UK
}

\section{Emilia den Boer}

Assistant Professor, Wrocław University of Technology, Institute of Environment Protection Engineering, Wroclaw, Poland

\section{Bernd Kopacek}

Managing and Research Director, Austrian Society for Systems Engineering and Automation (SAT), Vienna, Austria

Sabine Schadlbauer

Researcher, Austrian Society for Systems Engineering and Automation (SAT), Vienna, Austria

\section{Jörg Musterle}

Researcher, Austrian Society for Systems Engineering and Automation (SAT), Vienna, Austria

Business-to-business waste electrical and electronic equipment systems are not reported under current European Union regulations. This paper examines the independent, unreported, industrial networks for the collection and treatment of such waste in the UK, Austria, Germany, Romania and Spain. Methods used are semistructured interviews and surveys of relevant literature. The results show that treatment options are highly driven by the end market for the resulting product. Reuse rarely occurs in Austria and Spain, but is common in the UK and prevalent in Germany. The flow of equipment through different recovery/disposal routes cannot be estimated. It is concluded that a solution needs to be developed to avoid negative sustainability impacts, but which does not place such a burden on the industry that it makes the practice unattractive.

\section{Introduction}

Business-to-business (B2B) electrical and electronic equipment (EEE) includes equipment used by small to medium-sized enterprises (SME), large businesses and public sector organisations. Coordination of collection and treatment following business use is independent from municipal authorities (unlike that from households; see Ongondo and Williams, 2012) and is undertaken by organisations ranging from those that are manufacturer owned/supported to private companies. B2B waste electrical and electronic equipment (WEEE) systems are not reported under current EU regulations and thus there is no accountability for substandard treatment practices.

Business-to-business WEEE is regulated by the EU WEEE directive (European Commission, 2003), but it does not account for these networks. Recycling rates under the WEEE directive are reported as a fraction of the mass of EEE recycled in year $X$ divided by the mass of EEE 'put on the market' in year $X+1$ (European Commission, 2011). In 2009, more than $300000 \mathrm{t}$ of non-household (B2B) EEE were put on the market in the UK, of which $113000 \mathrm{t}$ were information technology (IT) equipment (Butler, 2010). According to the latest EU reporting figures, $7189 \mathrm{t}$ of end-of-life B2B IT equipment was collected in 2008 in the UK, that is, just $6 \cdot 3 \%$ of that put on the market a year later. Producer (manufacturer) responsibility organisations (PROs) report the amount of WEEE processed; these figures make up the bulk of the EU statistics, but other organisations that collect and treat $\mathrm{B} 2 \mathrm{~B}$ WEEE are under no obligation (nor is it to their advantage) to follow suit (Environment Agency, 2009; Eurostat, 2009). These organisations aggregate B2B WEEE before distributing whole units, components, materials and waste to brokers, commercial recyclers and waste managers and account for at least some of the remaining 93.7\%. Project ZeroWIN ('Towards zero waste in industrial networks' - www.zerowin.eu) is an EUfunded project researching and trialling (by means of case studies with industrial partners) methods and strategies to eliminate the wasteful consumption of resources in key industrial sectors in Europe, primarily by way of the formation of industrial networks. This ZeroWIN case study was developed to describe the current situation of B2B WEEE collection and treatment in EU member states and propose improvements, including policy recommendations.

\subsection{Business-to-business WEEE}

It is perceived that there is little B2B WEEE in the returning business to consumer (B2C) stream. It has been suggested that manufacturer take-back accounts for a minority of units on the 
market and there is no separate treatment infrastructure implemented and regulated by the government, as with B2C. Compared with the quantities that are sold, a relatively small amount of B2B WEEE is reported and the datasets are very incomplete (Eurostat, 2009). Consequently, it is important to engage with users and collectors of B2B EEE to understand better EEE asset management, particularly at end of life, to determine the fate of WEEE in the B2B system.

Magalini and Huisman (2007) noted that the difficulties presented when differentiating B2B EEE from B2C had led to difficulties in financing collection and treatment. They concluded that an approach based on waste arisings, rather than what was sold, would be more sensible. They also argued that certain streams of WEEE were exclusively B2B or B2C, putting IT in the B2C category. This is a debatable point; however, treating WEEE as it arises would clarify the B2C/B2B differentiation issue as they appear at different points in the waste stream.

The supporting document to the WEEE directive revision explicitly refers to the $\mathrm{B} 2 \mathrm{~B}$ streams, noting that a large volume is collected and unreported. It concludes that B2B WEEE should be included in the proposed collection target of the recast WEEE directive for environmental, economic and social reasons (European Commission, 2008). The UK-based charity Computer Aid addressed the issue of unreported end-of-life B2B IT in 2011 (Bourne, 2011). After interviewing 100 IT decision-makers for B2B IT at end of life, Bourne (2011) discovered that although $83 \%$ of respondents were aware of their legal obligations, one in five was not confident that their units avoided landfill.

Waste electrical and electronic equipment can be damaging to the environment if not correctly treated following disposal (Ongondo et al., 2011). EEE also contains some materials that are becoming increasingly scarce and have significant financial value (Ongondo et al., 2011). It is therefore important to collect and treat WEEE effectively to ensure scarce resources are not wasted, to avoid the detrimental environmental impacts of improper treatment, to mitigate the dwindling availability of virgin materials and to conserve potential value.

This case study examines the independent, unreported, industrial networks for the collection and treatment of B2B WEEE in five EU member states: UK, Austria, Germany, Romania and Spain. Building on the ZeroWIN project's vision and framework (Curran and Williams, 2012), the goals were to determine the nature and extent of the operations of organisations outside producer responsibility systems and to recommend strategies for improving collection and treatment. The objectives were to (a) determine structures, governance and drivers (such as business models) of current systems

(b) outline strategies for policy and reporting to improve B2B WEEE collection and treatment

(c) identify what extra knowledge would be required to implement any recommendations.

Figure 1 shows the baseline (current) scenario for flows of B2B WEEE within the ZeroWIN scope and boundaries. While there are existing processes to recapture financial value from the resources within these networks, there are flows of WEEE that can be inefficient and damaging, both environmentally and socially. It is difficult to determine the quantities of EEE that flow into the different networks. Figure 1 shows where the case study intervenes to develop strategies to improve collection and treatment. It was suspected that the majority of users disposed of their B2B WEEE through these channels. Also, the alternative routes (including leakage into the B2C stream, landfill, illegal export and dumping), can be socially or environmentally damaging and often contravene existing legislation. In an ideal scenario, these routes would not exist, so are not the focus of the case study. They are not discounted, as this would be would be unrealistic, but the goal of the case study is to engage with collection and treatment networks that already exist and make recommendations to improve practice and throughput; this is why the parties within the boundary shown in Figure 1 are the focus.

\section{Experimental methods}

The goals of this study are qualitative by nature (e.g. organisation structures, business models). Consequently, data on organisation structure and drivers were gathered through semistructured interviews with collecting organisations of different sizes. While a formalised set of questions was used, the questions were open ended to add richness and flexibility (Altheide and Johnson, 1994).

In each of the studied member states, organisations that collect B2B WEEE were approached through the professional networks of the ZeroWIN consortium partners. Snowball sampling, where new subjects are referred to the researcher by those who are initially engaged, was used because the population was unknown and there was little incentive for participation, and in most cases no existing relationship.

Question topics for the semistructured interviews were based on an approximation of the collection and treatment process for B2B WEEE, informed by the aforementioned preliminary discussion. This overview is presented in Figure 2. A collector would need to procure the units from an end-user, then treat or recondition them to sell on the second-hand electronics or materials markets. As end-users sometimes share in the profits of third-party collectors from reselling units, this potential for 


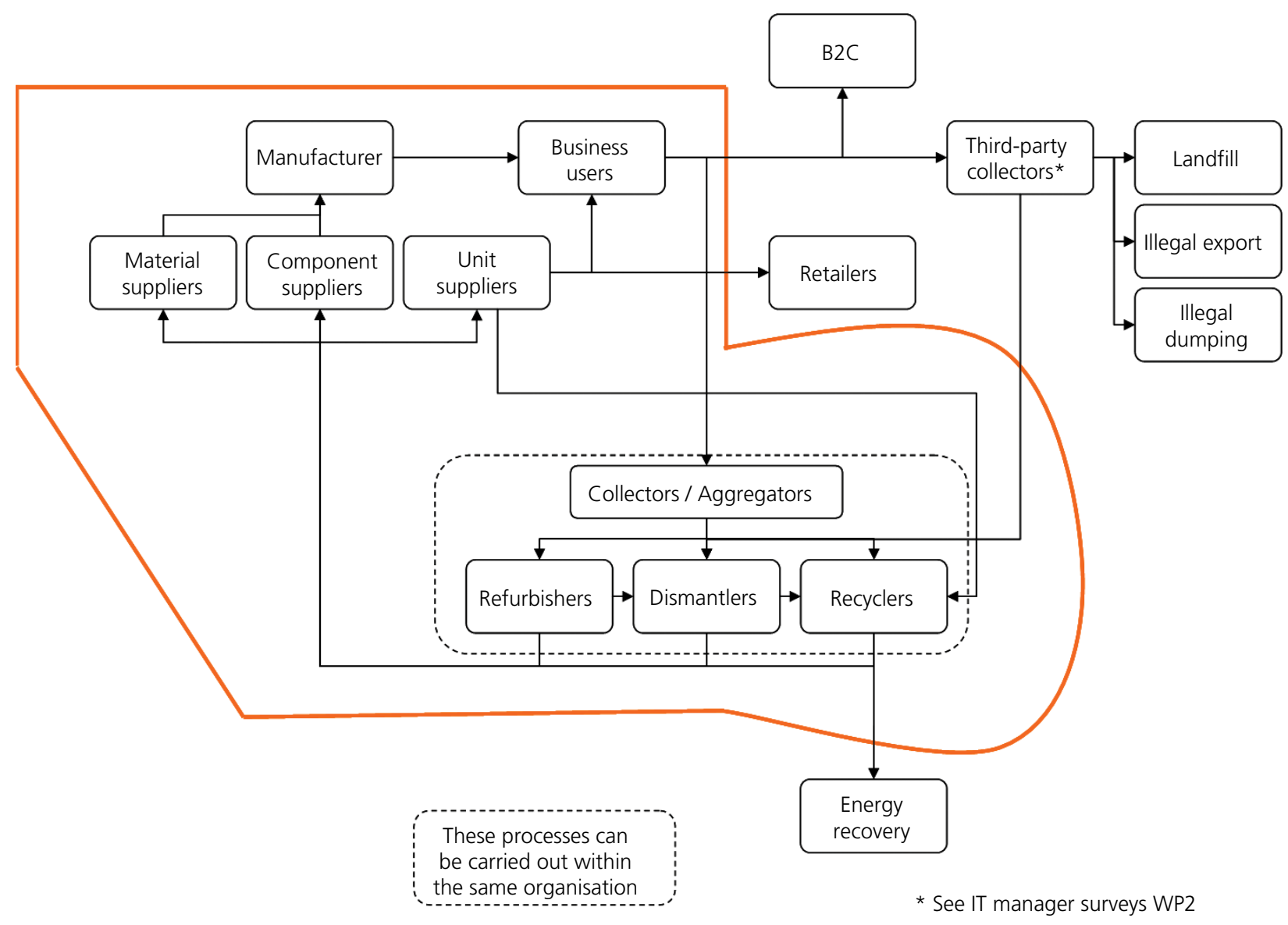

Figure 1. Baseline scenario for case study 10; a high level overview of current B2B WEEE collection and treatment networks

feedback was explored. The motivations behind the question headings in relation to the goals of the study are listed below.

Topic 1: Collection. As the input to the system, collection practice made a logical starting point to gather data. To begin the investigation of business models and drivers, interviewees were encouraged to discuss the business relationships between collector and end-user, including the development of pricing structures and procurement strategies. Subcontracting practices were also discussed, to ensure a complete overview of the chain of actors was collected, as well as the mix of products.

- Topic 2: Internal operations. The majority of the information collected came from discussions of internal processing routes and unit turnover. Knowledge of the decisionmaking processes during remanufacture, recycling and resale were developed for the analysis of business models and drivers. Similarly, the details behind the decisionmaking processes when materials re-entered the market were discussed.
Topic 3: B2B EEE market. Details of the market in which the actors are competing informed the analysis of the drivers and incentives that commercial actors are subjected to when collecting and treating B2B WEEE. Information on market share, the influence of the materials market, revenue streams and overheads was collected to help construct and give context to the overview of the collecting organisations within the scope of the study.

The elements of objective $(b)$, that is, strategies to intervene for reporting and governance to improve collection and correctly apportion responsibility, along with the knowledge required to implement them, were developed based on the analysis of these data.

The data collected through the semistructured interviews were analysed in line with the guide by Schmidt (2004). In a material-oriented formation of the analytical categories, the notes taken during each of the semistructured interviews were transcribed and then collated into a single document. The notes 


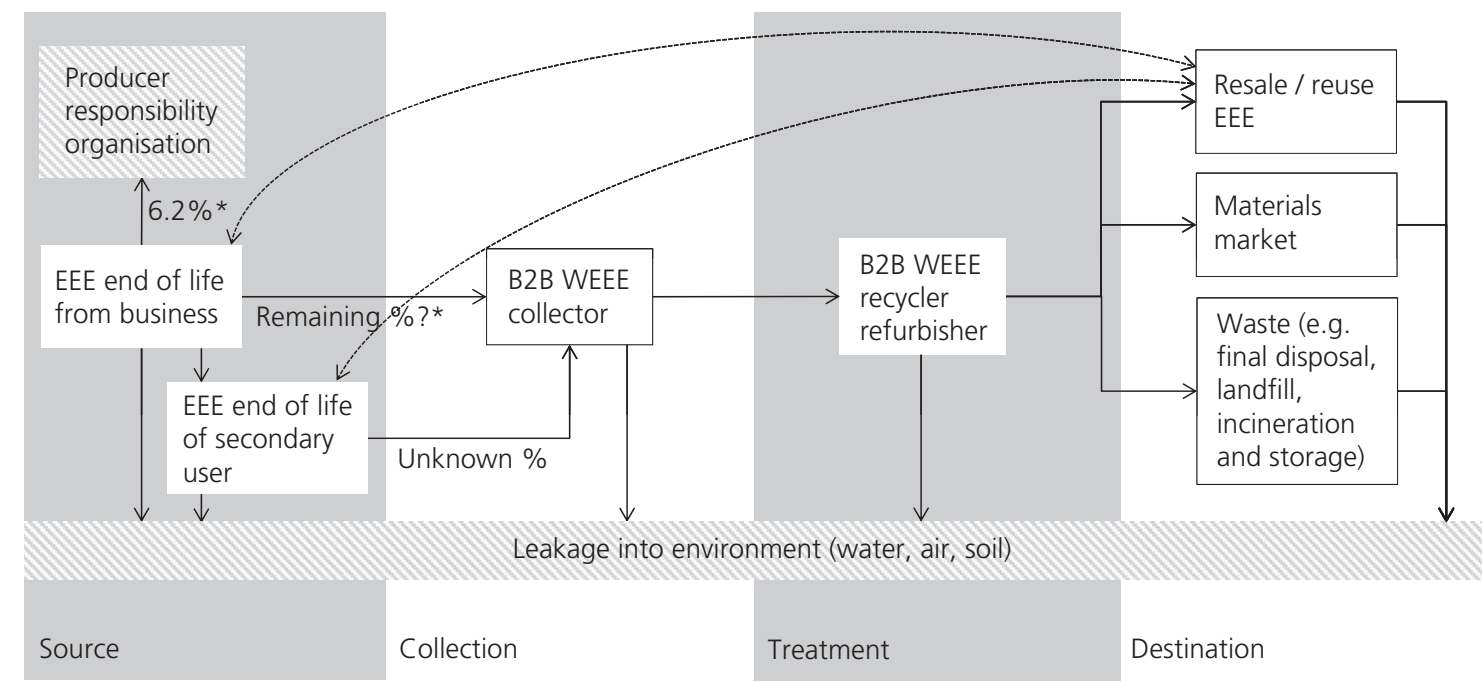

\begin{tabular}{|l|l|}
\hline$\longrightarrow$ & Physical flow \\
\hline$\longmapsto$ & Info or cash flow' \\
\hline & Actor \\
\hline & Out of scope \\
\hline
\end{tabular}

* Scope of B2B IT manager survey

† Where there is physical flow information or cash flow assumed present

Figure 2. High level overview of the business-to-business (B2B)

WEEE collection process developed before the study

from each interview were coded (using related terms and corresponding colours), and where they provided related or identical information they were clustered. These groupings were further refined with the strongest themes (as identified by the number of interviewees introducing the same information) as topic headers followed by the positions and the inputs of each contributor.

\section{Results}

\subsection{The UK}

Using the snowballing approach, three large B2B WEEE collectors were identified. The largest four to five collecting organisations were found to collect an estimated $60 \%$ of the WEEE. Additionally, two organisations, which turned out to be medium-sized actors, were contacted; these were found to collect an estimated $1 \%$ of the WEEE each. Finally, an industry association for private (therefore, de facto, largely $\mathrm{B} 2 \mathrm{~B})$ reuse and recycling of WEEE was contacted.

All the respondents discussed their organisation's market share to some degree, but estimates varied considerably. One organisation reported that they collected $3 \cdot 2$ million units in a year and estimated that their market share was $10 \%$ of B2B WEEE arising in the UK. One of the medium-sized organisations, which turned over 120000 units per year, estimated that they had a market share of less than $1 \%$. This would suggest that using the first company's estimate as a benchmark, their share should be $0 \cdot 375 \%$.

One interviewee estimated that there were around 400 organisations currently collecting B2B WEEE in the UK. The respondent said that $20-30$ of these had more than 20 employees (including the largest four to five, which they felt could account for $60 \%$ of all collected). Another confirmed this notion, stating that there were a few large organisations and describing the remaining industry as 'fragmented'. Two hundred of these organisations were reported to be one to two-person operations.

One respondent reported an increase in competition for access to B2B WEEE in the last 5-6 years. This position can be corroborated by interviewee statements that describe an increase in the number of collectors. This organisation claimed that a lot of the smaller organisations operate only for a small period of time. The representative of the smallest organisation interviewed (in terms of number of units collected) cited the recent global recession and an increase in scrap metal prices as incentives for smaller, one or two-person, operations to start collecting. The respondent noted that (at the time of the 
Waste and Resource Management

Volume 167 Issue WR4
Business-to-business end-of-life

IT industrial networks

Peagram, Williams, Curran et al. interview) an individual computer base unit was worth $£ 7$ on the scrap metal markets and that motherboards could attract $£ 6500$ per tonne. He said that a small organisation with low logistical costs could make a profit by stripping down obsolete EEE and selling the materials to more traditional scrap metal merchants, rather than to those in the authorised WEEE treatment routes. He said that these organisations often sell motherboards to UK-based accumulators who resell their stock to smelting organisations in Europe and Singapore.

Collection practices varied within the organisations themselves. Four out of the five organisations specifically detailed that a combination of their customers' preferences, location, number of units and security requirements determined collection practices. These four organisations also charged customers for collection.

Two types of B2B collection were discussed: 'roll outs' and 'clear outs'. The former involves the collection of a number of similar units 'off the desk' in the event, for example, of a workforce-wide hardware upgrade. These collections are prized in the industry; often these units are still in good working order and there are a number of units of the same model, which makes them easier to process and sell. There is a lot of competition for these 'roll outs' and potential customers of the third parties often release tenders for a number of collecting organisations to bid for. 'Clear outs' are when customers decide to dispose of redundant or broken units, often after having built up a stock over time. These are less attractive than 'roll outs' as the stock is frequently made up of older, non-functioning units and equipment models can be mixed.

Processing depended on both the customers' wishes and the potential profitability of the product. It was perceived that standard equipment that is available in large volumes is a commodity and has a calculable value. Certain models were worth sending for reuse but only in sufficient quantities. For other models there was more profit to be made through material recovery channels.

Different organisations had different approaches to deciding whether or not to prepare a unit for reuse and look for a buyer. One stated that if it would take longer than 20 min to bring a unit 'to market' then it would not be worth processing. This organisation held regular meetings to discuss the current market for reusable equipment and noted that units could become obsolete very quickly. Another described a graded scale of unit quality. The largest organisation noted that they did not single out likely units for reuse as this would be unprofitable; they said that the complex treatment requirements would only be viable for larger quantities of standard units.
The units for which reuse was not financially viable were recycled. The organisations then tried to reclaim value through the international materials markets. Units were dismantled and stripped down into streams of ferrous, non-ferrous and plastic streams, and then sold to metal smelters and reprocessors. A respondent from one of the organisations speculated that a large proportion of $\mathrm{B} 2 \mathrm{~B}$ WEEE was being mistreated as scrap metal.

The destination of the materials depended on the specific stream; for example, cathode ray tubes (CRTs) required specialist treatment; motherboards would typically go to copper smelters (typically to the Umicore plant in Belgium); non-ferrous materials would generally go to a smelter (again, often to Umicore); ferrous materials would often be sold to organisations in Turkey, Spain and India. The destination could change based on market activity; the larger organisations surveyed would monitor international materials prices to target their selling.

Most of the organisations stated that they generated more revenue through reuse markets, but as it was only viable to sell multiple units of specific models they had to recycle to reclaim value from the remaining WEEE. One of the large organisations noted that recycling costs could be prohibitive for smaller organisations who could only afford to resell the WEEE they collect. The largest organisation noted that there were a number of parties from different industries who could be handling the material and thus the material was difficult to track as it moved through the networks. Another noted that some units were in working order, but unsuitable for the UK used hardware market, and may be exported.

\subsection{Austria}

During the Austrian study, Figure 3 was developed to map out the potential routes for B2B WEEE. The routes identified included return to the manufacturer, leasing organisations, collection for treatment and recycling and donation to either employees or charities.

End-users were engaged to discuss their WEEE disposal practices. Large organisations often leased their units from third parties, or outsourced their entire IT function, so were not responsible for disposal. Some respondents indicated that if they did renew their IT systems themselves, they often would sell their used IT devices to their employees. Some organisations would have arrangements with EEE manufacturers or retailers who would dispose of old units when replacing them with new ones. Three organisations were engaged with, revealing a range of options. While this survey was not to the scale of the preceding study of IT end of use, it showed that the routes documented in the UK, Germany and France were also present in Austria. 


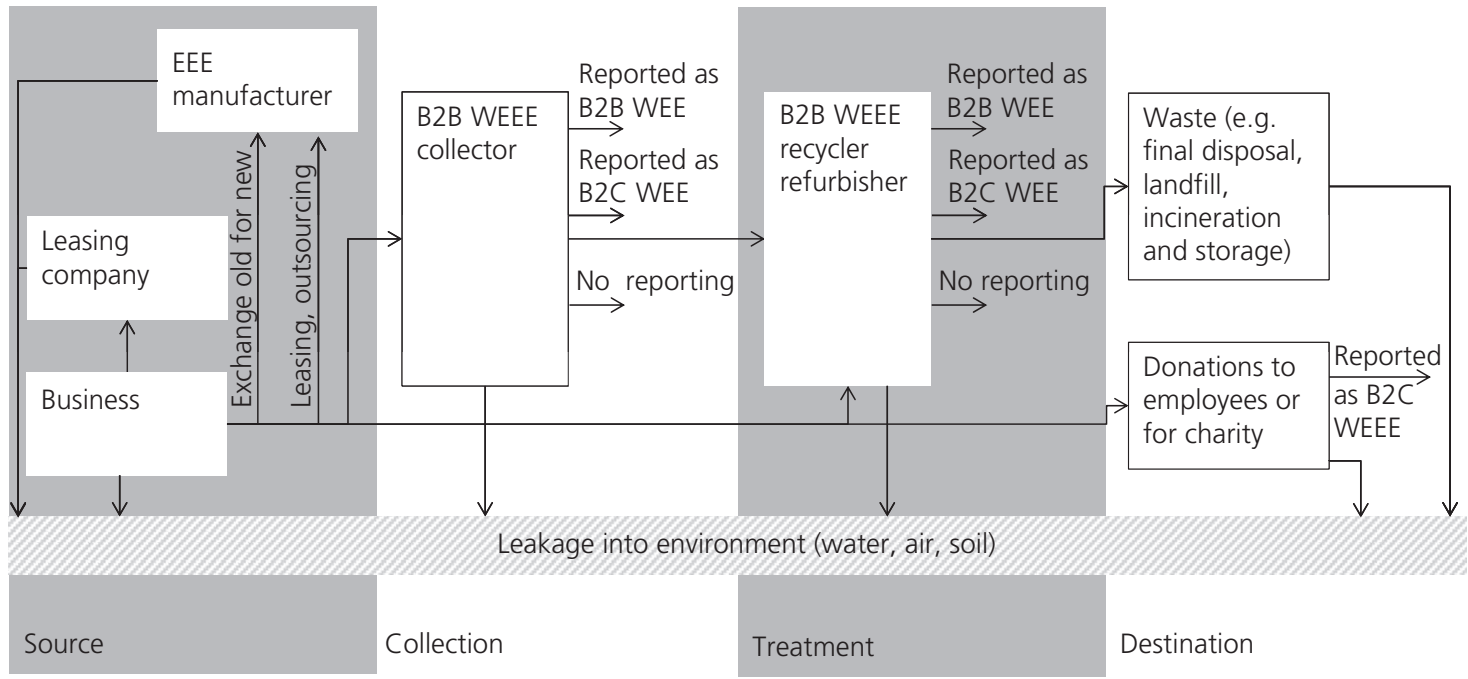

\begin{tabular}{|l|l|}
\hline$\longrightarrow$ & Physical flow' \\
\hline & Actor \\
\hline & Out of scope \\
\hline
\end{tabular}

† Where there is physical flow information or cash flow assumed present

Figure 3. Austrian flow of business-to-business (B2B) WEEE.

'No reporting' indicates the possibility that no official record of the transaction was recorded

Organisations that leased IT units were also contacted as background to the study. One respondent was sure that $99 \%$ of their customers were business users. Three leasing organisations were contacted and asked what happened to end-of-use units; their responses are listed in Table 1.

Representatives from 12 (large and small) organisations involved in B2B WEEE collection were interviewed. The largest were involved in general waste treatment, which included WEEE, and some of the smaller ones were dedicated to the product type. In Austria, it was found that many organisations were limited geographically in their collection footprint, which reduced competition for collection. Two explicitly stated that there was no competition, but one said that there was competition for circuit boards. Most organisations said that they would accept any product that arose (legally) and many said that they had no preference.

The largest organisations offered a collection service, regularly visiting their clients who had a high turnover of WEEE. They

\section{Organisation Details of operations at leased unit end of use}

A

When the contract expires (normally after 5 years) there are two outcomes

(a) the customer keeps the device (around $10 \%$ of units)

(b) the leasing company takes back the device.

Either

- the leasing company loans the device to another customer (around $45 \%$ of units)

the leasing company sends the devices for disposal (around $45 \%$ of units).

B

Most customers buy the IT products after the contract runs out (those units that are in good condition). The remaining units are returned and are sold into a pool of asset brokers.

C Disposal of WEEE is included as part of the service.

Table 1. The fate of leased unit at end of use in Austria 
also offered an 'on demand' service. There was a mix of contract collection and on-demand work in all of the other organisations as well. No others mentioned regular, scheduled, collection. Many organisations used multiple collectors, but there was a mix between these and long-lasting relationships.

Organisations would often charge customers for collection; it depended on the quality and the aggregation of the WEEE being collected. Two organisations charged for collection but could share profits with their customers, while two did not charge and did not share. All of the organisations fulfilled the legal requirement of reporting the quantities and product type to the Elektroaltgeräte Koordinierungsstelle Austria $\mathrm{GmbH}$ (EAK). One collected more detailed data, photographing each unit. This organisation charged for collection and was involved in profit shares with its customers.

None of the organisations resold their products for reuse and one speculated that few organisations in Austria did (aside from not-for-profit social enterprises). All parties recycled the units they collected and sold on the materials. Nine of the 11 organisations said that they were unable to tell the age of the units that they collected. One noted an increase in flat-screen monitors, which it said would be quite new, but did not give an age. One said that the photocopiers they collected were between 5 and 6 years old. In all cases, the resources would be sold internationally if this was the most financially rewarding practice. One noted that transport costs needed to be considered when selling the materials outside the EU. One noted that most circuit boards were sold to The Netherlands.

All of the respondents would sell their materials to the party making the best financial offer; this could be to a materials broker, or it could be another party, and this could change regularly. All organisations said that selling metals was the most profitable aspect of their business. The most profitable materials would depend on the current market; one would store materials while the price was low, anticipating a rise. The estimated market share of the organisations varied significantly and two did not want to guess. All organisations stated that their share was small, although one disagreed with their fellow respondents' estimate of their own market share.

One noted that scrap metal dealers collected a lot of WEEE, but said if asked then they would deny this, as it is illegal. Many noted that the recent economic crisis had driven new actors into the sector, looking to exploit the resources the sector contains. Industry-wide data on collection are available from the EAK; these are presented in Table 2.

In a report for the Austrian Federal Ministry for Environment in 2005 , by GUA $\mathrm{GmbH}$, the authors proposed possible reasons for the differences observed between $\mathrm{B} 2 \mathrm{~B}$ and $\mathrm{B} 2 \mathrm{C}$
Mass collected: $\mathrm{kg}$

$\begin{array}{lr}2006 & \\ \text { EEE market } & 156809009 \\ \text { B2B EEE market } & 7527623 \\ \text { WEEE collected } & 63878485 \\ \text { B2B WEEE collected } & 1249989 \\ \text { 2007 } & \\ \text { EEE market } & 167194206 \\ \text { B2B EEE market } & 9109347 \\ \text { WEEE collected } & 67467608 \\ \text { B2B WEEE collected } & 2942979 \\ \text { 2008 } & \\ \text { EEE market } & 171666550 \\ \text { B2B EEE market } & 8136703 \\ \text { WEEE collected } & 69625872 \\ \text { B2B WEEE collected } & 4167868 \\ \text { 2009 } & \\ \text { EEE market } & 159994346 \\ \text { B2B EEE market } & 6246945 \\ \text { WEEE collected } & 76338746 \\ \text { B2B WEEE collected } & - \\ \text { 2010 } & \\ \text { EEE market } & 165811276 \\ \text { B2B EEE market } & 7371575 \\ \text { WEEE collected } & 75564487 \\ \text { B2B WEEE collected } & 1309019\end{array}$

Table 2. Collection weights for disposed EEE in Austria

collection rates (B2B collection was considerably lower). The report suggested that one reason could be that reporting at collection points was often incorrect; the authors suspected that small organisations were disposing of B2B but stating that it was B2C. It was also suggested that organisations, such as metal recyclers, intervene to dismantle the WEEE before reporting takes place, adding further opacity to whether the WEEE is $\mathrm{B} 2 \mathrm{~B}$ or $\mathrm{B} 2 \mathrm{C}$.

\subsection{Germany}

Approximately $40 \%$ of WEEE (related to annual EEE production) is collected formally. There are around ten large recycling companies, which were assumed to collect the greatest share of the market (although no exact figures were available). Researchers found a perception among industry contacts that very few units were reused $(<1 \%)$. Units that are collected formally are shredded, with the remainder incinerated for thermal energy production.

Information was obtained from a large collector of B2B EEE, which processed around 226000 B2B units per annum. This organisation focused on information and communications technology, with a preference for collecting newer models and 
personal computers. They engaged with their customers for collection through direct acquisition and through referrals from other organisations. They had regular contracts with disposing organisations and noted that their customers rarely used more than one organisation.

The financing of collection (e.g. profit shares, directly purchasing units) depended on the quality of the goods, which they would collect themselves. Metrics, including brand and model, would be recorded for all units collected. These metrics were reported online through their own system. A value assessment was made, based on unit age and quality, when deciding whether either to recycle or reuse units. These items would be cleaned and repaired, if necessary. The units that they collected tended to be between 4 and 8 years old. Some units would be sent for component recovery if they could not be reused. The organisation reported that some units left the country following treatment; these were tracked through internal systems. The organisation sold materials to intermediary brokers and noted that the most profitable revenue streams were highly variable.

The case study engaged with three smaller organisations, the representatives of which did not state the number of units that they collected (self-described as 'small'). Two of these collected personal computers, laptops and monitors, and the third also collected servers. Most approached their customers through referrals from other organisations. They noted that there was a lot of competition for B2B WEEE between vendors of used equipment and producer take-back schemes.

All three respondents said that treatment options were based on the wishes of the customer. They also noted that they often had to pay for equipment and that disposers would use multiple organisations to get the best price for their WEEE. Profit shares between the disposer and collector were common, but depended on the treatment requirements. If a customer wanted the hard drive of their units to be deleted, for example, they would have to pay for this service and there would be no profit share. As well as direct collection, these organisations would buy WEEE from large, aggregating vendors. One of the respondents claimed that they recorded metrics (brand, model) from their units, but noted that there was no one to report them to. Two of the others did not collect any metrics.

The collectors would assess the age and condition of units before performing a value assessment of whether to recycle or reuse, based on the associated treatment costs and the likely profits. All three noted that if a unit is reusable, more profit could be gained by reusing it rather than recycling the materials. If a unit is recycled, then it is worth dismantling the unit into material fractions and components to sell individually. Two noted that selling the plastics was not profitable.

Two respondents noted that their organisation sold materials and units for reuse both nationally and internationally, with no monitoring. They noted that prices changed daily, so they monitored the materials and reuse markets. Two said that there were no industry-wide data on B2B WEEE collection, so they were unable to estimate their market share. One estimated that for B2B WEEE, $10 \%$ was collected at local collection points, $2 \%$ through social enterprises, $50 \%$ through large brokers and $1 \%$ through SMEs (by volume).

\subsection{Spain}

Semi structured interviews were not possible in Spain and hence a literature review was necessary. The WEEE directive was transposed to 15 autonomous communities and two autonomous cities in Spain. In total, around $40000 \mathrm{t}$ of B2B WEEE were collected in 2004. Huisman et al. (2008) estimated that $112800 \mathrm{t}$ of B2B EEE were sold in Spain in 2005. Using this as a benchmark, the collection rate for WEEE is around $35 \%$. Some $31000 \mathrm{t}$ of B2B IT and telecommunications equipment were put on the market in Spain in 2005 and the researchers found that $606 \mathrm{t}$ were managed through reported systems in 2004 (Eurostat, 2009; Huisman et al., 2008). A total of 12 WEEE management schemes were identified for Spain and nine industrial recyclers. There were several smaller organisations involved in reuse; generally these were not-forprofit organisations.

Activities were apparently more focused on recycling and recovery than on reuse. For the recycling and recovery of B2B WEEE, there are a number of integrated waste management systems that collect both B2B and B2C. Some of these organisations are specific to WEEE categories or even a type of equipment. There are a number that focus on WEEE and others that also treat end-of-life vehicles and non-ferrous metals.

Reuse activities are mainly carried out by non-industrial companies: small organisations that collect and repair equipment and tend to be social enterprises. While most reuse organisations are small or not for profit, there are some large, international, commercial organisations. These companies usually offer B2B services (logistics and collection of the old equipment, reuse under permission, data destruction certification and environmental compliance handling). In 2010, Spain identified that as much as $70 \%$ of WEEE from all sources was escaping official channels to be treated illicitly (Ends Europe, 2011).

\subsection{Romania}

In 2010, the volume of WEEE collected in Romania was around $25000 \mathrm{t}$. Sixty per cent of this was made up of white 


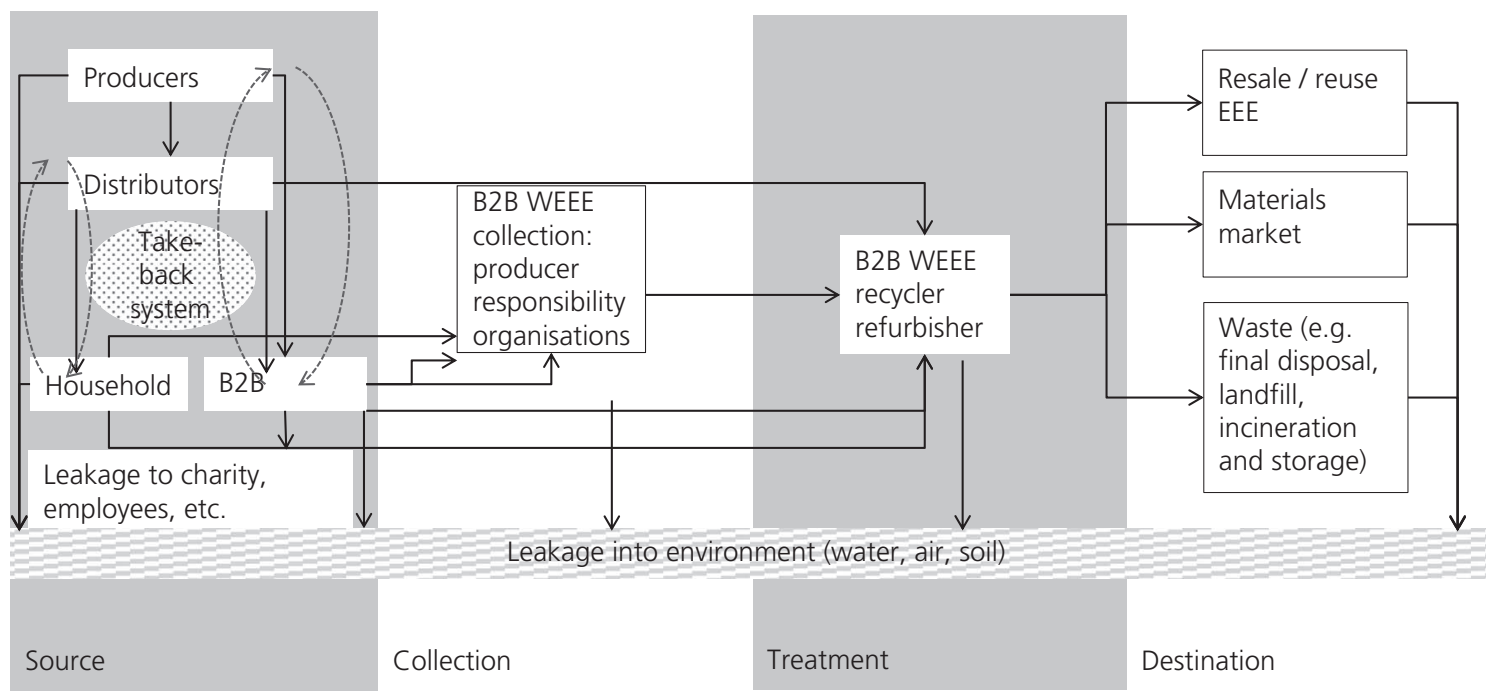

Legend
\begin{tabular}{|l|l|}
\hline$\longrightarrow$ & Physical flow ${ }^{\dagger}$ \\
\hline & Info or cash flow \\
\hline & Actor \\
\hline & Out of scope \\
\hline
\end{tabular}

t Where there is physical flow information or cash flow assumed present

Figure 4. WEEE management systems in Romania, including

business-to-business (B2B)

goods, $15 \%$ were CRTs or TV screens, $20 \%$ was IT and $5 \%$ were tools and small appliances (by volume). In the Romanian system, B2B and B2C WEEE are collected together (see Figure 4). Romania has the lowest WEEE collection rate per capita $(0.8 \mathrm{~kg})$ in the EU (Eurostat, 2009). Total WEEE collected for both streams (B2B and B2C) was $9 \%$ of that put on the market. However, for IT and communications equipment (the largest category of B2B), the rate of collection is 34\% of that put on the market (2008), which is a similar figure to many other EU member states (Heironymi, 2009).

Within Romania there are five producer responsibility organisations; one of these has a $60 \%$ share of the white goods arising and another has a $35 \%$ share of the IT and communications equipment. These organisations account for around $90 \%$ of the WEEE that is reported as collected. There are ten organisations that recycle WEEE and six of these are in the southeast of the country.

Once B2B EEE users were ready to dispose of their units, they either returned them to the producer or distributor; gave them to charities or employees (or they were leaked) internally; had them collected by a producer responsibility organisation; or sent them directly to a recycler. Dismantled units entered the materials market through these recyclers. Some were also disposed of.

There was resistance to the collection of detailed data for the study and an unwillingness to discuss operations. This meant that the relative quantities that flowed through each channel could not be determined. However, as $9 \%$ placed on market (POM) was reported as collected, these 'visible' systems account for a minority of the potential B2B WEEE arising.

\section{Discussion}

4.1 Networks, governance, barriers and incentives A summary of the five countries' B2B WEEE systems, based on responses from interviews, is provided in Table 3. Reuse was shown to be common in the UK and prevalent in Germany, whereas it was solely the practice of social enterprises in both Austria and Spain. As reuse is considered to be the most preferred option from a sustainability perspective, the structure and decision making behind the UK and German systems was explored. Information about the structure of the current networks was gathered from the details of collection and treatment practices for B2B WEEE and the 
UK

Austria

Germany

Romania

Spain
Collection practices vary

- Customer preferences largely determine collection practices

Two types of B2B collection: 'roll outs' and 'clear outs'

Estimated that the largest 4-5 collecting organisations collect $\sim 60 \%$ of the B2B WEEE

400 Organisations currently collecting B2B WEEE, 20-30 of these having $>20$ employees

- Customers often charged for collection

- Collection practices vary

- Organisations typically offer only limited geographical spread for collection

Mix of contract collection and on-demand work

Some profit sharing with customers

- Collection practices vary

- Customer preferences largely determine collection practices

- Financing of collection depends on quality of units; some profit sharing with customers

- 40\% of WEEE is collected formally

- Around ten large recycling companies were assumed to collect greatest market share but no figures available

- Small organisations buy EEE from large, aggregating vendors

- Collection practices vary

B2B and B2C WEEE are collected together

- Five producer responsibility organisations account for $\sim 90 \%$ of reported collections

- For IT and communications equipment, collection rate reported as $\sim 34 \%$ of that put on the market

B2B WEEE collection rate estimated as 35\%

- Some organisations collect both B2B and B2C WEEE

- 12 WEEE management schemes identified nine industrial recyclers

- Large organisations often charge for collection; smaller organisations tend to be not for profit

Up to $70 \%$ of WEEE from all sources escaping official channels
- Processing often depends on customers' wishes and potential profitability

- Time and quality dictate whether units are prepared for reuse, prepared for component recovery or recycled

- Destination of materials depends on specific WEEE stream

- More profit in reuse than recycling

No evidence that organisations sell collected materials for reuse

- 'Illegal' selling of WEEE by scrap metal dealers allegedly widespread

Destination of materials depends on best financial offer

Processing often depends on customers' No data wishes and potential profitability

Time and quality dictate whether units are prepared for reuse, sent for component recovery or recycled

Destination of materials depends on specific WEEE stream

More profit in reuse than recycling

Resistance to collection of data and an No data unwillingness to discuss operations

Activities more focused on recycling

Estimated at than reuse $>112000$ t/year
Estimated at 300000 t/year (12-32 million units/year)

Estimated at 〜 160000 t/year
- Destination of materials depends on specific WEEE stream 


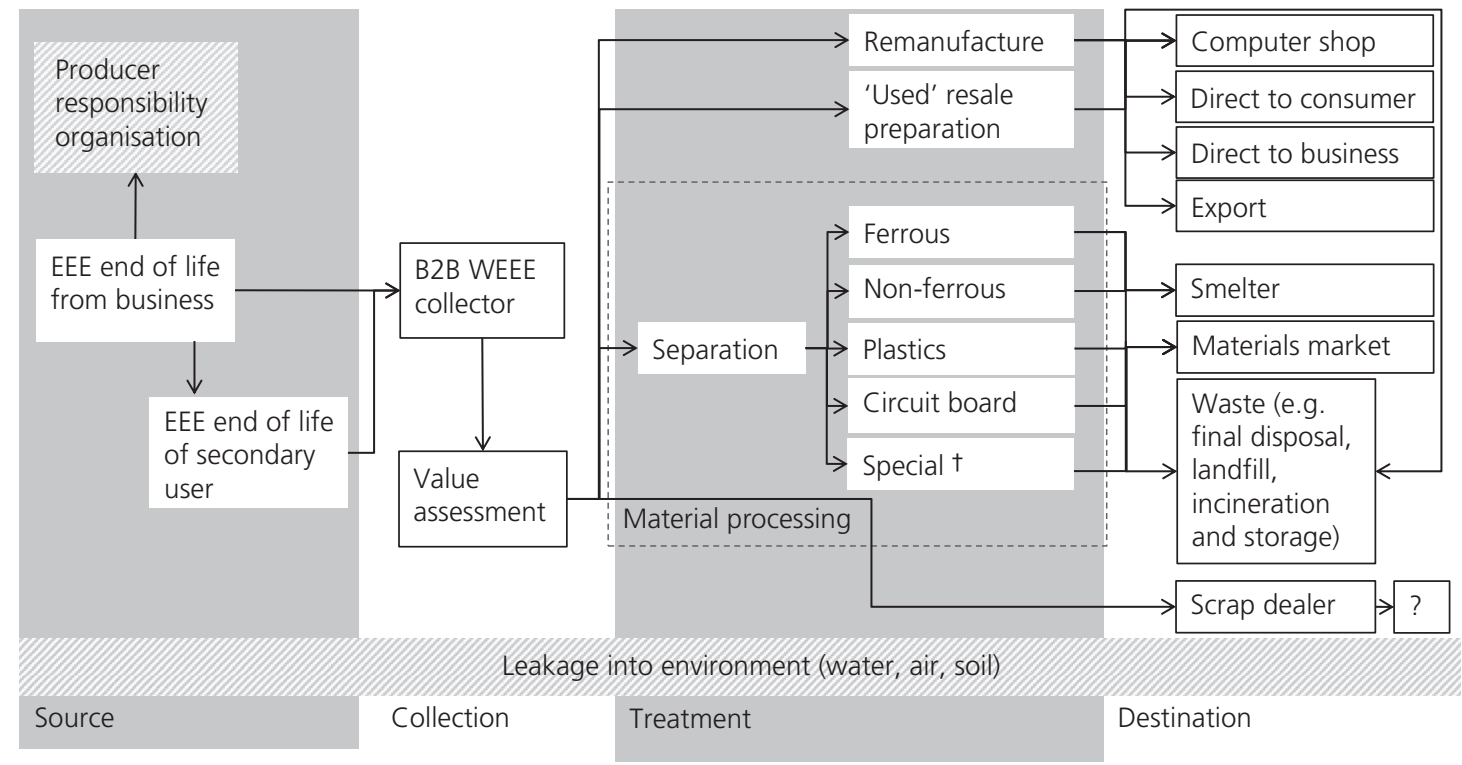

\begin{tabular}{|l|l|}
\hline$\longrightarrow$ & Physical flow $^{\dagger}$ \\
\hline & Actor \\
\hline & Out of scope \\
\hline
\end{tabular}

+ Where there is physical flow information or cash flow assumed present

Figure 5. Materials flow for business-to-business (B2B) WEEE from collection through treatment for reuse or recycling in UK and Germany. Special + includes unusual (one-off) or non-standard items. 'Leakage into the environment' is possible from every step, to simplify the illustration, the arrows are not plotted

units per year, similar pathways were in place, albeit at different scales. While smaller, one to two-person collecting organisations were not interviewed, their operations were discussed with their larger counterparts and, based on the data gathered, it is considered reasonable to suggest that these pathways would be similar to those illustrated by materials flow for B2B WEEE from collection through treatment for reuse or recycling.

Once an organisation collects WEEE, it makes an assessment on whether it would be more profitable to process the units for reuse or for the materials markets. Should reuse be the preferable option, units are treated to a standard where they can be sold; this treatment can range from cleaning and repackaging to remanufacture. Should reuse not be profitable, units are processed to reclaim their embodied materials. Materials are separated into streams of commodities: ferrous and non-ferrous metals, plastics, circuit boards and those requiring special treatment such as CRT glass. The more streams the materials are split into, the 'purer' they are and as such can command a higher price. There is a trade-off between the cost of disaggregating the materials and the increased price of the 'purer' commodity. Greater disaggregation requires more specialist treatment, which comes at a cost. Some treatment options require large quantities of WEEE to achieve the economies of scale necessary to make them a profitable endeavour. These options are not available to smaller organisations, which can only make a profit through selling more aggregated streams of materials. One large and one medium-sized respondent both suggested that the only value recovery pathways that would be economically viable for one or two-person organisations would be through local, traditional (non-WEEE specialist), scrap metal brokers rather than on the international materials markets that they used. Organisations in many countries speculated that a significant quantity of B2B WEEE was being mistreated locally as scrap metal. This approach makes financial sense in the UK and Germany, but as the practice was not present in Austria and Spain there is no value assessment; all that is collected goes into the left branch of Figure 5.

Figure 6 shows the factors driving material flows and influencing the value assessment between the reuse and recycling routes in the interviewed organisations in the UK 


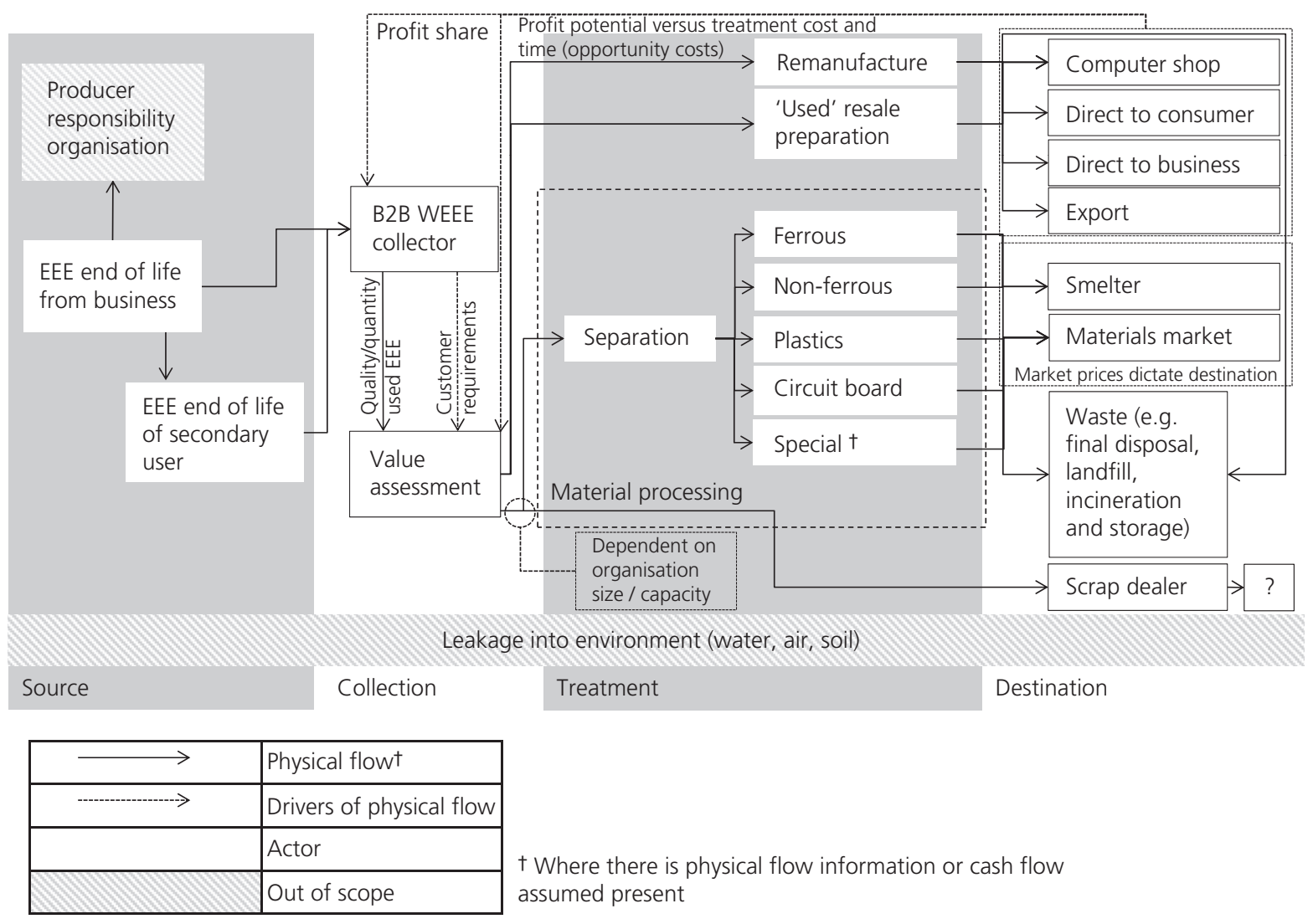

Figure 6. Drivers of materials flow for business-to-business (B2B) WEEE from collection through treatment for reuse or recycling. Special + includes unusual (one-off) or non-standard items. 'Leakage into the environment' is possible form every step, to simplify the illustration, the arrows are not plotted

and Germany. Collection and treatment practices were strongly influenced by the users: their attitude to security and traceability dictated the collectors' practices. The quality, that is, the model and brand, and the quantity of the WEEE units strongly influenced this decision. Large quantities of standard, relatively new, equipment could be easily resold and as such were likely to be reused. As noted earlier, competition for these streams is high. Conversely, mixed and small quantities of older non-functioning units would be almost impossible to resell and would be recycled. There is a trade-off between the potential profits to be made through resale and the costs of treatment: both the technical costs and the opportunity costs of the time invested in the treatment. It was also noted that there was a feedback loop to the user; profit sharing from resale was described as standard industry practice and some customers approached the collectors with the specific motivation of reclaiming value from their redundant assets.
The intrinsic value of the materials in WEEE was highlighted as a possible driver of the increased number of collectors observed in the UK and Austria. Reuse, however, is the more profitable option, for those units where it is viable (which was apparently never in Austria or Spain), and as such preferable. Should reuse not have been viable, the units were processed to recover value from the materials. The actors interviewed monitored the international markets for materials to decide where to sell each stream, mentioning Spain, India and Turkey. In both the reuse and the recycling pathways, the extent of the dispersal of materials increases along the chain, thus reducing the traceability of the WEEE.

In Austria, the collectors of B2B WEEE were subject to stricter reporting laws than the other member states, having to declare their collection rates to the EAK. This showed that, in 2010, $17 \cdot 8 \%$ of B2B WEEE put on the market was collected. In 
Waste and Resource Management

Volume 167 Issue WR4
Business-to-business end-of-life

IT industrial networks

Peagram, Williams, Curran et al.
Germany, Spain and Romania it was impossible to determine B2B collection rates. Detailed analysis was possible in the UK from the respondent's answers.

The interviewees were consistent in estimating that there were around 400 organisations collecting B2B WEEE in the UK, that approximately 20 of these (i.e. $5 \%$ ) had more than 20 employees and that 150 (i.e. $37 \cdot 5 \%$ ) were one to two-person operations with a turnover of less than $£ 175000$ per annum. The market outside the top 20 largest organisations was described as 'highly fragmented'. Given this fragmentation and the inconsistencies in estimated market share from larger organisations, it is difficult to determine precisely how much WEEE flows where. Tonnages of B2B EEE put on the market are available through manufacturers' reporting for the WEEE directive; however, WEEE arising is recorded by the government for B2C only. As noted earlier, 300000 t B2B EEE were put on the market in the UK in 2009, of which $113000 \mathrm{t}$ were IT and telecommunications equipment (Butler, 2010); the largest fraction of B2B EEE sold. These figures are reported by mass, whereas the interviewees discussed how much their organisation collected by number of units. It is argued that this reflects how most interviewees viewed their businesses; commodities are sold by mass whereas EEE is sold by the unit and despite increasing materials prices all the interviewees, excluding the representative of the largest organisation (in terms of reported volume collected), noted that reuse was the most profitable treatment option for them. HP own data on WEEE; this includes information on the mass of WEEE units arising. The median mass for a unit of IT equipment (excluding accessories, i.e. mouse, camera, etc.) was $5 \cdot 355 \mathrm{~kg}$. Using this value as a representative per-unit mass, 21101774 B2B IT units were sold in the UK in 2009 , that is $113000 \mathrm{t} /(5 \cdot 355 /$ 1000). As the interviewees consistently estimated that the majority of the units they processed were 3-4 years old, the market figures for 2009 (or 2008) would be the most relevant to the B2B WEEE arising in 2012 (when the interviews were carried out)

\subsection{Strategies for policy and reporting}

In Austria, two of the B2B WEEE collection organisations said that they 'did not like' WEEE collection (many of the organisations surveyed were general waste brokers) due to the associated administration. In Austria, collectors are obliged to report on everything they collect. In the UK, in the absence of such a system, nearly all of the B2B WEEE is thought to be collected, and reuse is commonplace (albeit market driven). The findings for the UK are similar to those of Huisman et al. (2012) in their study into WEEE flows in The Netherlands; they concluded that nearly all B2B WEEE was being collected. A possible explanation for the lower collection rates, and the lack of reuse in Austria, could be that the financial burden of the administration associated with reuse is too great to make the value assessment shown in the UK and Germany worth considering.

The results of the interviews from the UK and Germany show an existing, competitive, industry trading in B2B WEEE - one that is not covered by current WEEE directive reporting, with organisations collecting and treating for reuse and recycling without process channels defined by legislation as with B2C WEEE (European Commission, 2003). As these are private businesses, there is a focus on profit. The more attractive WEEE units are often treated for reuse by both large and small collectors and the larger collectors recycle. Some units flow into channels where the capacity to treat WEEE (as opposed to traditional metals recovery) is not financially viable, particularly those controlled by smaller scale actors.

Business-to-business WEEE needs to be accounted for and correctly treated. The fact that private organisations currently exploit WEEE for financial gain, however, does not automatically have adverse environmental and social impacts. Providing all WEEE, regardless of quality, can be accounted for and it is treated to an acceptable standard, there is no reason to interfere in the existing competitive collection and treatment industry. Should current actors be given a mechanism to declare their share of the market (to enable the assurance of adequate coverage in total) and treat to an acceptable standard, suitable collection and treatment networks for B2B WEEE could be in place already.

A solution that addresses these actors needs to be developedone that considers not only the drivers of the system, but also the value in reuse and resource exploitation, and the barriers that affect decision making. Placing too much of a burden on reporting could make collection and processing unprofitable, resulting in low collection rates and no reuse; this is a trend that could be occurring in Austria already. There is, however, a pressing need for accountability that has the sustainability of the system at its centre, to avoid negative impacts. Also, the system needs to be secure and accurate, or issues of fraud could arise, as observed in Spain (Ends Europe, 2011). Intervention cannot be completely based on profitability and private enterprise, as commercial interests can make collecting meaningful data very difficult.

\subsection{Knowledge requirements}

In light of the above findings, it is recommended that the collection rates of the largest collecting organisations are officially confirmed (outside Austria). Some of these organisations already report data for the B2C WEEE they collect and treat, and simple mass data would be sufficient to determine an organisation's total collection share from the sales figures provided by manufacturers for WEEE directive reporting (usually on an annual basis), so implementation would be 
feasible. There could be resistance from the actors within the system, some of whom perceive that details of their market share are commercially sensitive. One actor noted that there could be incentives for actors to submit incorrect collection figures. Given that there is a small number of larger organisations, third-party verification of collection figures could be feasible. Also, if these data were to be anonymised, then the actors may be less resistant. If these data on the collection process are posed to the actors as fulfilling the need to account for the WEEE rather than interfering in their businesses, provided that there is no need to interfere, then the reporting process could be more acceptable. These larger actors already treat materials to a high standard, because many of their customers demand it and they are providing them with a service.

Smaller actors control some of the WEEE arisings and, regardless of the size of this fraction, the units that they do collect need to be treated correctly. This smaller fraction of the WEEE arisings is widely distributed, so accounting for it all could be a challenge; WEEE cascades into smaller streams as it moves through these networks. Some of the interviewees noted that the smallest organisations sold the units they collected, which were not financially viable for reuse, to traditional scrap metal brokers. This contravenes current regulations and these organisations do not have the capacity to treat WEEE properly. They do, however, represent a point of aggregation for the WEEE streams, so could represent a more feasible place in the system to intervene for regulation. If they could be monitored and encouraged to steer any WEEE that comes under their control into channels with the capacity to meet the appropriate treatment requirements and mechanisms for recording the flows, then WEEE that is dispersed through the smaller collecting organisations could be properly accounted for.

There is evidently a degree of uncertainty regarding what constitutes 'used EEE' as opposed to 'WEEE' (and other terms in use such as 'end-of-use EEE' and 'end-of-life EEE'). Some may not regard WEEE that is subsequently reused as WEEE, particularly if it is reused through informal channels; for example, when a previously used television is given to another family member; conversely if EEE is not reusable or is obsolete it may be given the label 'WEEE' and, consciously, not 'used EEE'. It may be worthwhile for follow-on research to ascertain, and clarify, the extent to which this nomenclature issue is (only) one of popular usage or the uncertainty stems from the use of multiple terms in regulatory documents across Europe.

\section{Conclusion and recommendations}

There are widely different practices and cultures relating to B2B WEEE management systems in Europe. Reuse rarely occurred in Austria and Spain, but was common in the UK and prevalent in Germany; in Romania, there was significant resistance to collection of data and an unwillingness to discuss operations. While the potential value of WEEE from a materials perspective has been discussed widely (e.g. Ongondo et al., 2011), for the UK B2B WEEE collectors, reuse was shown to be the most profitable option for the units where it was possible. Whether or not a unit was viable for reuse depended on the likelihood of its sale and the costs of its treatment when compared with the potential profit. This comparison was shown to be highly sensitive to change, reviewed on a daily basis, and many functional units were not worth processing for reuse. The value assessment was shown to be completely market driven and the requirements of the market were highly specific and variable. Organisations do pro-actively collect certain units with the intention of reclaiming materials, so it would follow that the units they select are based on the potential market as well.

This sensitivity needs to be considered in policy moving forward; EEE needs to be accounted for and there are organisations that willingly take account, but in many cases this information is not captured. These findings are highly relevant to ongoing discussions on producer responsibility, waste entrepreneurship and the management of WEEE. The recommendations to account for more B2B WEEE, the good practice highlighted, and the exposure of the barriers and incentives that influence reuse and materials recycling will be invaluable to realising the ZeroWIN vision in this sector.

\section{Acknowledgements}

The research leading to these results has received funding from the European Community's Seventh Framework Programme (FP7/2007-2013) under grant agreement no. 226752. The authors would also like to acknowledge contributions from: Sixto Arnaiz and Maitane Gallo (Gaiker); Cristian Aionesei (Greentronics); Kirstie McIntyre (Hewlett Packard); and Johannes Dietrich (Technical University of Berlin).

\section{REFERENCES}

Altheide DL and Johnson JM (1994) Criteria for assessing interpretive validity in qualitative research. In Handbook of Qualitative Research (Denzin NK and Lincoln YS (eds)). SAGE, Thousand Oaks, CA, USA, pp. 485-499.

Bourne V (2011) Press release. See http://www.computeraid. org/news-detail-pr.asp?ID=123 (accessed 12/07/2013).

Butler S (2010) Lobbying Action Group (Compliance Scheme WEEE Reporting). ERP UK Ltd, Chiswick, London, UK. Environment Agency (2009) Waste Electrical and Electronic Equipment (WEEE). Environment Agency, Rotherham, UK. See http://www.environmentagency.gov.uk/business/ topics/waste/32084.aspx (accessed 01/08/2010).

Curran T and Williams ID (2012) A zero waste vision for industrial networks in Europe. Journal of Hazardous Materials 207-208: 3-7.

Ends Europe (2011) Report Reveals Massive WEEE Fraud in 
Spain. The Ends Report, Environmental Data Services, Teddington, UK.

European Commission (2003) WEEE directive 2002/96/EC. Official Journal of the European Union L37: 24-38.

European Commission (2011) Proposal for a directive of the European Parliament and of the Council on waste electrical and electronic equipment (WEEE). See http://register. consilium.europa.eu/doc/srv? $=\mathrm{EN} \& \mathrm{f}=\mathrm{PE} \% 2062 \%$ 202010\%20INIT (accessed 03/09/2014).

Eurostat (2009) Waste Electrical and Electronic Equipment, Data 2006. See http://epp.eurostat.ec.europa.eu/cache/ITY_SDDS/ EN/env_waselee_esms.htm (accessed 03/09/2014).

Heironymi K (2009) Material issues in manufacturing electronics. Proceedings of International Workshop on Environment and Alternative Energy, Garching, Germany.

Huisman J, Magalini F, Kuehr R et al. (2008) 2008 Review of Directive 2002/96 on Waste Electrical and Electronic Equipment (WEEE). ENV.G.4/ETU/2006/0032. United Nations University, Bonn, Germany.
Huisman J, van der Maesen M, Eijsbouts RJJ et al. (2012) The Dutch WEEE Flows. I. SCYCLE. United Nations University, Bonn, Germany.

Magalini F and Huisman J (2007) Management of WEEE and cost models across the EU: Could the EPR principle lead US to a better environmental policy? Proceedings of the 2007 IEEE International Symposium on Electronics and the Environment, Orlando, FL, USA, pp. 143-148.

Ongondo F and Williams ID (2012) A critical review of the UK household WEEE collection network. Proceedings of the Institution of Civil Engineers - Waste and Resource Management 165(1): 13-23.

Ongondo F, Williams ID and Cherrett TJ (2011) How are WEEE doing? A global review of the management of electrical and electronic wastes. Waste Management 31(4): 714-730.

Schmidt C (2004) The analysis of semi-structured interviews. In A Companion to Qualitative Research (Flick U, von Kardorff E and Steink I (eds)). SAGE, London, UK, pp. 253-257.

\section{WHAT DO YOU THINK?}

To discuss this paper, please email up to 500 words to the editor at journals@ice.org.uk. Your contribution will be forwarded to the author(s) for a reply and, if considered appropriate by the editorial panel, will be published as discussion in a future issue of the journal.

Proceedings journals rely entirely on contributions sent in by civil engineering professionals, academics and students. Papers should be 2000-5000 words long (briefing papers should be 1000-2000 words long), with adequate illustrations and references. You can submit your paper online via www.icevirtuallibrary.com/content/journals, where you will also find detailed author guidelines. 